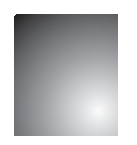

\title{
Marketing Social Corporativo: estado da arte e PROPOSIÇÃO DE UM ESQUEMA CONCEITUAL
}

\author{
Corporate Social Marketing: state of the art and proposition of \\ a conceptual model
}

Francisco Giovanni David Vieira

Professor Doutor da Universidade Estadual de Maringá, UEM - Maringá - PR - Brasil. E-mail:fgdvieira@uem.br

Agnaldo Keiti Higuchi

Diretor de Graduação da Universidade Federal dos Vales do Jequitinhonha e Mucuri - Teófilo Otoni - MG - Brasil. E-mail: agnaldo. higuchi@ufvjm.edu.br

\section{Rosemeri Schneider}

Professora e Instrutora da Instituição: Caixa Econômica Federal - Maringá - PR - Brasil. E-mail: roseschneider@uol.com.br

\section{Patricia Soares Azoline Correa}

Profissional de Comunicação Social da Petrobrás S.A. - Itajaí - SC - Brasil. E-mail: psacorrea@hotmail.com

\section{Resumo}

A discussão sobre o desenvolvimento de ações sociais por parte de empresas, em regra, tem estado vinculada à concepção de marketing social. Originariamente vinculada à ação do Estado para a resolução de problemas sociais e para incentivar mudança de comportamento da população, essa concepção é reducionista e trata a iniciativa empresarial de marketing no campo social como sinônimo de filantropia, responsabilidade social ou marketing de causa social. $\mathrm{O}$ artigo enfoca essa questão, ainda não resolvida teoricamente no âmbito da disciplina, e propõe uma nova concepção para o desenvolvimento de ações sociais por parte das empresas, a qual é sintetizada em um esquema conceitual de marketing social com caráter corporativo. Para tanto, faz-se um balanço do estado da arte e são assinalados antecedentes, questões gerenciais, marcos teóricos, nomenclatura e categorias de análise de marketing social corporativo. Ao término, são apresentados pressupostos, taxonomia, proposições básicas e a aplicação do esquema conceitual.

Palavras-chave: Marketing. Social. Corporativo. Esquema Conceitual.

\section{Abstract}

The debate about the development of social initiatives by business has usually been linked to the concept of social marketing. Founded on a platform originally linked to State action to solve social problems and attempt to promote change in the population behavior, this conception is reductionist and see the marketing initiative in social matters as synonymous of philanthropy, social responsibility or marketing of social cause. This article focuses on this issue, which is still unresolved theoretically within the discipline, and proposes a new concept for the development of social initiatives by business, which is synthesized in the proposition of a conceptual scheme of social marketing with a corporate character. In this way, it is approached the state of the art and are mentioned backgrounds, managerial issues, landmarks, nomenclature, and categories of corporate social marketing. At the end, the article presents assumptions, taxonomy, basic propositions and a conceptual scheme.

Keywords: Marketing. Social. Corporate, Conceptual Scheme. 


\section{INTRODUÇÃO}

O envolvimento corporativo em ações sociais na comunidade começou na forma de ações voluntárias de empresas que visavam a solucionar ou a amenizar problemas sociais. Essas ações de filantropia corporativa, na forma de doações para instituições de caridade, têm sido praticadas desde o final do século XIX nos Estados Unidos em que, por exemplo, contribuições voluntárias faziam parte da agenda das companhias que podiam arcar com tais despesas (BRONN; VRIONI, 2001). A partir de 1960, ainda segundo Bronn e Vrioni (2001), começaram a se difundir noções de que as corporações possuíam responsabilidades que iam além das obrigações legais.

Brown e Dacin (1997) postulam que, diferentemente da habilidade corporativa, que se relaciona com a expertise da organização em produzir e entregar bens e serviços, as ações sociais corporativas refletem o status e as atividades da organização; ou seja, a percepção pelo público de como a organização está respondendo às pressões sociais. Segundo esses autores, a reputação corporativa passa, então, a ser função não somente das características funcionais dos bens e serviços ofertados, mas também dependente, em parte, da imagem corporativa como socialmente responsável.

Nos negócios, as iniciativas sociais corporativas foram definidas como práticas de políticas no relacionamento com a sociedade, que visam satisfazer as necessidades da sociedade (ANGELIDIS; IBRAHIM, 1993), uma vez que tais políticas são consistentes com expectativas e valores sociais existentes (LERNER; FRYXELL, 1988; PEATTIE; PEATTIE, 2009; FREITAS; REZENDE, 2010). Uma forma de contribuir para o bem-estar da sociedade é por meio de campanhas que objetivem uma mudança cognitiva nas pessoas, de forma que estas abandonem comportamentos ou atitudes prejudiciais ao convívio social. Estas campanhas foram historicamente compreendidas como sinônimo de marketing social.

Kotler e Zaltman (1971) introduziram o termo marketing social em 1971 para descrever o uso de princípios e de técnicas de marketing para a promoção de uma causa, ideia ou comportamento social. Tais autores definem o marketing social como esforços no sentido de alterar crenças, atitudes, valores ou comportamento de determinado público-alvo. Marketing social, assim, leva ao mercado ideias em lugar de produtos ou serviços, que visam à mudança cognitiva de ação, no comportamento e nos valores (KOTLER; ZALTMAN, 1971). Em outras palavras, o marketing social busca a modificação no comportamento das pessoas, de forma que faça com que elas abandonem atitudes que podem trazer malefícios tanto ao indivíduo quanto à coletividade (ANDREASEN, 2003). $\mathrm{O}$ processo de marketing social exige a pesquisa de marketing e o desenvolvimento de apelos bem concebidos que, para atingir o público-alvo, são vinculados em comunicações em mídias de massa. Tais ações, por abrangerem questões sociais de interesse do Estado, são feitas normalmente em parceria com entidades governamentais. (KOTLER, 1978; MASSÓ, 1998)

Na década de 1990 surgiram argumentos de que ações sociais, quando desempenhadas por corporações, não eram totalmente altruístas. Varadarajan e Menon (1988) mencionam que a filantropia corporativa engloba uma variedade de atividades e, dentre elas, algumas que podem afetar positivamente a lucratividade da corporação (COLLINS, 1993; FILE; PRINCE, 1998). Assim, o pensamento dominante de Friedman (1962), que defendia como única responsabilidade social da corporação a geração de lucro para seus acionistas, foi gradativamente sendo substituído pela convicção de que essa responsabilidade deve ser considerada como um investimento que pode melhorar o desempenho da organização em longo prazo.

Para tanto, as ações sociais devem ser incorporadas à estratégia de marketing da corporação, ou seja, os objetivos de melhorias sociais devem fazer parte também dos objetivos estratégicos de marketing (VARADARAJAN; MENON, 1988; HASTINGS, 2003). Como citam Smith e Higgins (2000), de uma perspectiva corporativa, o consumidor abandona, em parte, a busca por satisfação material somente e, também, inclui em suas demandas a satisfação moral, que pode ser entendida como a preocupação com o próximo ou com o meio ambiente, por exemplo, ou ainda por perceber a existência de um risco social. (DOUGLAS, 1966)

Surge, então, na segunda metade da década de 1980, o marketing de causa social, que se originou em um contexto marcado pelo encolhimento do Estado em suas obrigações sociais (PRINGLE; THOMPSON, 2000; SAIZ, 2005), o que abriu espaço para a atuação da iniciativa privada na solução de problemas sociais, 
complementando as ações governamentais. Segundo Massó (1998), o marketing de causa social é entendido como as ações que buscam associar o nome da corporação ou de uma marca a uma causa social relevante, e que exigem o engajamento do consumidor. Nesse caso, uma parte da receita das vendas de determinado produto é destinada para o investimento em ações sociais, produzindo resultados de duração limitada.

No início dos anos de 1990, as empresas perceberam que, caso planejassem melhor e desenvolvessem de forma mais duradoura as atividades que antes eram executadas de maneira esporádica e dispersa, elas poderiam ser convertidas em um componente poderoso da estratégia de marketing (SAIZ, 2005). As atividades sociais, que tinham o propósito simples de responder a questões ou compromissos referentes a uma causa pontual, tornaram-se, assim, atividades realizadas de forma contínua e divulgadas sob um enfoque de marketing corporativo, de modo que o alvo relaciona-se aos consumidores que desejam fazer a diferença na sociedade por meio do consumo de produtos e/ou de serviços de empresas que investem em programas de ações sociais corporativas. (BRONN; VRIONI, 2001)

Smith e Alcorn (1991) postulam que o marketing social corporativo combina os elementos do marketing tradicional com conceitos estabelecidos pela responsabilidade social corporativa, já que em sua estratégia estão presentes, simultaneamente, o senso de responsabilidade social e a busca pela satisfação dos stakeholders por meio de melhores produtos, maior lucratividade e participação de mercado. Segundo Ptacek e Salazar (1997), para inteirar-se sobre os fundamentos do marketing social corporativo é preciso entender os motivos dos diferentes atores sociais envolvidos: as organizações filantrópicas procuram por fontes de fundos para suas atividades; as corporações buscam aumentar suas vendas e reforçar sua imagem perante seus stakeholders; os consumidores desejam responsabilidade social e qualidade por um preço justo.

A relevância deste tema, para a área de marketing, está nos benefícios que tais programas podem trazer tanto para a sociedade quanto para as empresas (MAZZON, 1982; HASTINGS; SAREN, 2003; BATES, 2010). Um programa de marketing social corporativo pode fazer com que os interesses particulares de cada ator caracterizem-se como necessidades atendidas em razão da sinergia gerada no relacionamento entre os diferentes atores (PTACEK; SALAZAR, 1997). Tal sinergia, porém, carece da aplicação de um esquema conceitual que oriente as ações da corporação, de modo que elas sejam executadas de forma coordenada. Em que pese essa observação, atualmente os conceitos $e$ as nomenclaturas utilizados pelas empresas não apresentam uma unicidade ou um consenso (MAIGNAN; FERRELL 2004, SEN; BHATTCHARYA 2001), fato este que pode gerar resultados indesejados na atuação social. Programas mal-elaborados podem fazer com que os stakeholders criem interpretações equivocadas, em que a parceria com a causa seria vista como uma exploração da causa, contribuindo assim de maneira negativa para a reputação e a imagem corporativa. (MORETTI, 2010)

Este artigo propõe um esquema conceitual que pode auxiliar as organizações mostrando as possibilidades em posicionamento e em direcionamento para suas ações e projetos no campo social. Busca-se apresentar os aspectos envolvidos na evolução do tema, partindo da filantropia corporativa, passando pela responsabilidade social, marketing social e pelo marketing de causa social, até chegar ao esquema proposto para o marketing social corporativo. O esquema sugere, então, requisitos necessários para a elaboração, no que concerne à empresa, de ações sociais relacionadas a objetivos corporativos.

Posto isso, inicia-se este artigo com uma revisão de literatura sobre os antecedentes e a presença da questão social na produção científica em marketing. Em seguida são apresentados o esquema conceitual proposto, seus pressupostos e sua aplicabilidade. Nas considerações finais são apresentadas as implicações gerenciais e as teóricas do esquema e as sugestões para pesquisas posteriores.

\section{Revisão de Literatura: o estado da ARTE EM MARKETING SOCIAL CORPORATIVO}

Esta seção procura fazer um resgate e apresentar o estado da arte da literatura de marketing que trata de marketing social corporativo. Em termos específicos, ela compreende a indicação de alguns antecedentes e aspectos relacionados à questão social na produção acadêmica de marketing, aponta desdobramentos gerenciais da incorporação de questões sociais em mar- 
keting, promove um recorte histórico e assinala marcos teóricos e trata de nomenclatura e das categorias de análise convergentes em marketing social corporativo.

\subsection{Antecedentes e Presença da Questão Social na Literatura de Marketing}

A atuação das corporações nas questões sociais se iniciou com a adoção por parte delas do conceito de responsabilidade social. A origem do conceito de responsabilidade social está associada inicialmente às ações filantrópicas desenvolvidas no século XVIII nos Estados Unidos, mas sua discussão por acadêmicos iniciou-se com o lançamento do livro Responsibility of the Businessman, de Howard Bowen, também nos Estados Unidos, em 1953 (PINTO et al., 2004). Desde então, a responsabilidade social corporativa teve diversas conceituações. Partindo de uma visão econômica clássica, Friedman (1962) defendia que a única responsabilidade social da empresa era gerar lucro para seus acionistas. Tal argumento é justificado por Drucker (1996, p. 70) quando ele afirma que

[...] o desempenho econômico é a primeira responsabilidade de uma empresa. Uma empresa que não apresente um lucro no mínimo igual ao seu custo de capital é socialmente irresponsável. Ela desperdiça recursos da sociedade. $\mathrm{O}$ desempenho econômico é a base; sem ele não pode cumprir nenhuma outra responsabilidade, nem ser boa empregadora, uma boa cidadã, nem boa vizinha.

Desde então, a responsabilidade social corporativa passou por outras conceituações até chegar àquela em que é vista como parte do processo gerencial, incorporando a satisfação dos diversos stakeholders por meio de ações delimitadas pela ética (ALVES, 2003; MAIGNAN; FERREL, 2004; MORETTI; CAMPANÁRIO, 2009). Assim como o conceito de responsabilidade social, a literatura de marketing também teve seu período em que era baseada, principalmente, em teorias de economia de custos de transação, até incorporar o conceito de responsabilidade social corporativa e buscar sua sustentabilidade nos negócios. (ASHLEY; MACEDO-SOARES, 2001; PRADO; MERLO; CERIBELI, 2010)

\subsection{Aspectos Relacionados à Ação Social na Literatura de Marketing}

Nos anos de 1960, percebeu-se que a filantropia executada por ações assistencialistas das corporações, que tinham como objetivo a caridade sem perspectiva de retorno financeiro, poderiam ter sua abrangência ampliada com a utilização das técnicas de marketing. Surge então o marketing social, que, segundo Kotler e Zaltman (1971), se refere ao emprego de princípios e de técnicas de marketing para a promoção de uma causa, ideia ou comportamento, orientadas pela responsabilidade social corporativa.

De acordo com Maignan e Ferrel (2004), a responsabilidade social corporativa encontra no marketing contribuições valiosas para a realização de seus objetivos, assim como se encontram na literatura de marketing vários tópicos relacionados à responsabilidade social corporativa: respostas dos consumidores às iniciativas em responsabilidade social corporativa (BROWN; DACIN, 1997; SEN; BHATTACHARYA, 2001; MORETTI; FIGUEIREDO, 2007); a importância da ética e da responsabilidade social entre profissionais de marketing (VITELL; PAOLILLO; THOMAS, 2003); e o suporte às causas de caridade. (BARONE; MYAZAKI; TAYLOR, 2000)

Ao analisar as respostas dos consumidores com relação às ações sociais da empresa, vários autores verificaram que as ações sociais poderiam criar uma atitude favorável e trazer benefícios em termos de comportamento de compra (VARADARAJAN; MENON, 1988; BARONE; MYAZAKI; TAYLOR, 2000; BHATTACHARYA; SEN, 2004). As empresas passam então a investir em programas cuja meta principal é associar suas marcas a causas sociais consideradas pelo público como relevantes e com isso garantir benefícios na forma de maiores vendas ou margens de lucro. (HOEFFLER; KELLER, 2002)

Nos anos de 1980 surgiram as primeiras campanhas nas quais empresas comprometem-se a doar parte da receita das vendas de determinado produto a uma causa social. Essa forma de marketing com objetivos financeiros e sociais, que demandam a participação do consumidor, foi denominada, por alguns autores, como marketing relacionado à causa, ou marketing de causa social (ADKINS, 2005). O marketing de causa social surgiu em 1982 quando o então vice-presidente 
da American Express, Jerry Wells, mencionou o termo para batizar uma ação estratégica desenvolvida por sua empresa, a qual se propunha a destinar uma pequena porcentagem do gasto com cartão de crédito para a recuperação da Estátua da Liberdade. (PRINGLE; THOMPSON, 2000)

A partir dessa iniciativa muitas causas receberam investimentos provenientes dos programas de marketing de causa social (FOX; KOTLER, 1980). Esses programas, porém, eram esporádicos, possuíam um início e um término determinados e abrangiam vários tipos de causas diferentes. Essa falta de foco na ação social dificulta a identificação da empresa ou da marca a uma causa específica, limitando os benefícios trazidos pela atividade. Uma forma alternativa para associar a corporação a uma causa de forma mais consistente é proposta pelo marketing social corporativo.

Conforme Saiz (2005), o marketing social corporativo surgiu quando as empresas perceberam que, caso planejassem melhor e desenvolvessem de forma mais duradoura as atividades que antes eram executadas de maneira esporádica e dispersa, elas poderiam converter essas atividades em um componente poderoso da estratégia de marketing, trazendo benefícios em longo prazo. As atividades sociais, que tinham o propósito simples de responder a questóes ou compromissos referentes a uma causa pontual, tornaram-se, no marketing social corporativo, atividades contínuas.

O conceito básico do Marketing Social Corporativo (MSC), segundo Massó (1998), consiste em que as empresas identifiquem ações que possam ajudar a si mesmas melhorando ao mesmo tempo algum aspecto da sociedade, porém de forma estratégica e em longo prazo. Com isso, o principal objetivo é que o MSC busque uma mudança fundamental durante o tempo, trazendo benefícios principalmente para a imagem da marca. Organizações não lucrativas, por conseguinte, recebem o benefício monetário dessas doações, junto com um aumento da percepção pública, tornada possivel pelas habilidades de marketing da empresa.

A seguir, na Figura 1, explicita-se um resumo em que várias possibilidades de responsabilidade corporativa (RSC) são relacionadas às ações sociais das empresas e seus objetivos.

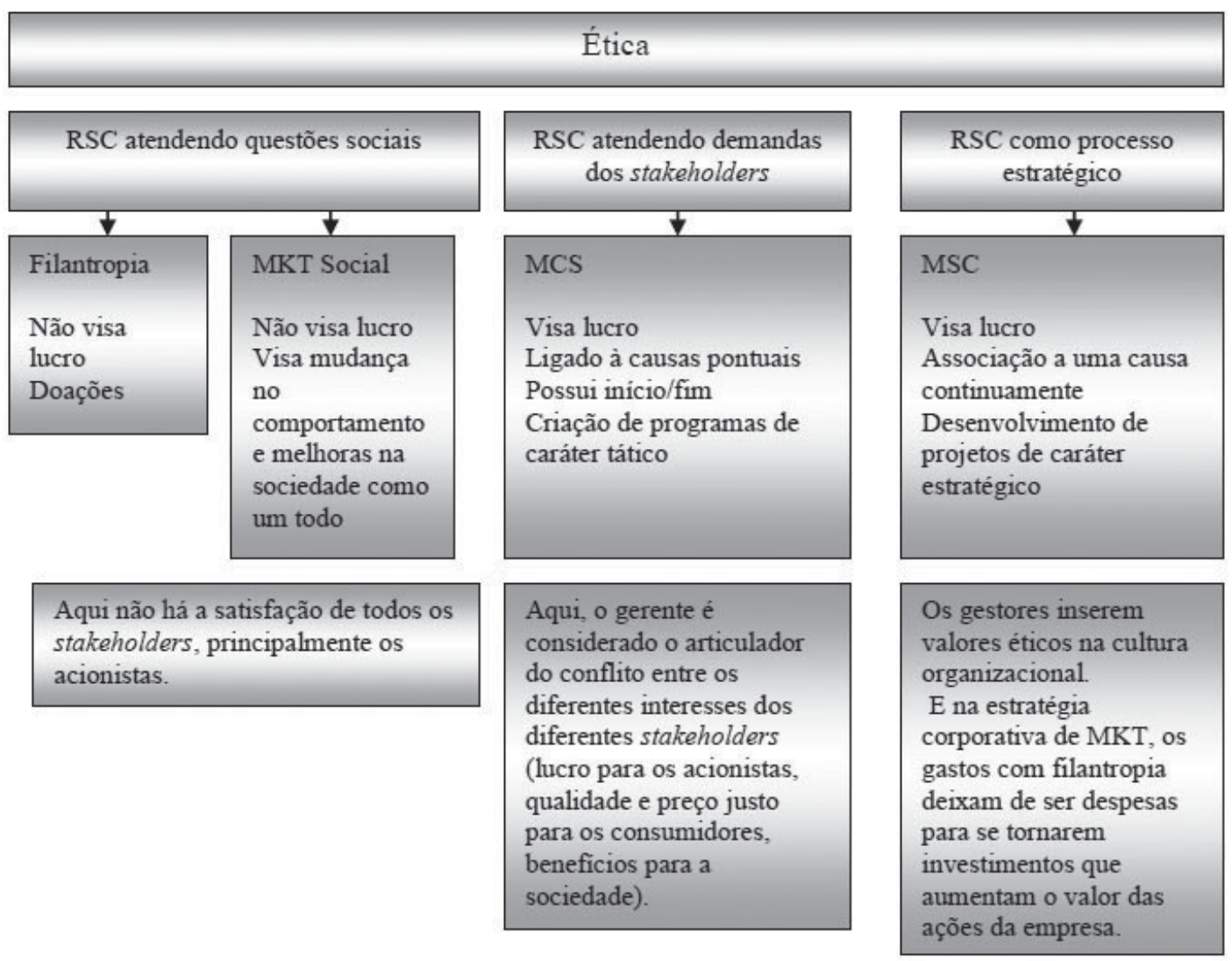

Figura 1: Presença da questão social na literatura de marketing

Fonte: Adaptada de Maignan e Ferrel (2004), Pringle e Thompson (2000) e Robin e Reindenbach (1987) 


\subsection{Desdobramentos Gerenciais da Incorporação das Questões Sociais em Marketing}

Ao executar suas atividades operacionais, a empresa deve seguir leis e normas que regulamentam sua interferência no meio ambiente, a relação com os funcionários e sua interação com o governo e outras empresas. Entretanto, seguir as regras não representa uma fonte de vantagem competitiva. A vantagem pode ser conseguida se ela for além das regulamentações legais de pagar impostos e do objetivo de gerar lucro $e$ se apresentar ações de responsabilidade social que beneficiem o ambiente e a coletividade com a qual se relaciona (PRINGLE; THOMPSON, 2000; MAIGNAN; FERREL, 2004). Essas atitudes precisam também perdurar em longo prazo, pois somente assim poderão superar o ceticismo e a desconfiança do consumidor. (WEBB; MOHR, 1998)

Para tanto, é importante ressaltar os três fatores mais presentes na literatura de marketing, para os quais os gestores de marketing dedicam atenção: a comunicação, a escolha da causa à qual se associam e a incorporação dos valores éticos e de responsabilidade social na cultura organizacional. Com relação à comunicação, Bronn e Vrioni (2001, p. 216-17) definem a situação nos seguintes termos:

Se as organizações não dizem o suficiente sobre suas ações de caridade, os consumidores acreditam que estas estão escondendo algo, mas se estas comunicam demais, eles acreditam que as causas estão sendo exploradas. Por isso, a promoção de tais ações de responsabilidade social corporativo é um dos trabalhos mais delicados do marketing social corporativo. Ir longe a uma direção fará os consumidores crerem que está se usando a causa, e ir à outra fará com que estes nem sequer saibam do envolvimento da organização.

As comunicações precisam ser planejadas de modo a minimizarem possíveis atribuições negativas ou desfavoráveis, evitando a impressão de que a organização está explorando a causa em lugar de auxiliá-la. O desafio de comunicar as ações dos programas de responsabilidade social corporativa torna-se complexo na medida em que diferentes stakeholders possuem expectativas distintas, necessitam de informações variadas, e principalmente, não respondem da mesma maneira aos diversos canais de comunicação disponíveis (DAWKINS, 2004). Para superar esse desafio, faz-se necessário que a corporação desenvolva uma estratégia de comunicação clara, com campanhas de comunicação que possuam mensagens, estilos e canais convenientes para cada público de stakeholders. (DAWKINS, 2004)

Além de comunicar de maneira clara, identificar uma instituição beneficente adequada para fazer parceria ou uma boa causa com a qual a empresa ou a marca possa se associar é também uma questão importante. Varadarajan e Menon (1988) assinalam que a escolha deve se basear no público a quem a causa desperta interesse, e que as melhores causas são aquelas com maior visibilidade na mídia e com potencial para gerar mérito. Outros aspectos a serem considerados são o escopo geográfico e as diferenças interculturais. Varadarajan e Menon (1988) classificam o alcance entre nacional, regional e local, ao passo que Bronn e Vrioni (2001) defendem que os valores que guiam as políticas, as decisões e os programas socialmente responsáveis são fruto de uma variedade de sistemas normativos advindos de culturas, religiões e educações diferentes.

A escolha precisa ser feita com cautela e profissionalismo, similarmente à escolha de parceiros de negócios, e deve ter os termos de relacionamento colocados em contratos e acordos formais (GARCIA, 2001). Com parceria ou associação, a empresa pode desenvolver um processo com benefícios potencialmente maiores para sua marca, mas que também incorrem em riscos potenciais. A melhor forma de maximizar os benefícios e de minimizar os riscos, segundo Pringle e Thompson (2000), é assegurar que haja a melhor harmonia possível entre os valores de marca desejados e aqueles que serão acrescentados a ela por meio da associação com a entidade filantrópica ou causa escolhida. Por isso, um dos aspectos mais importantes do marketing social corporativo é definir o território onde a personalidade da marca se posicionará a fim de garantir o desenvolvimento pleno de seu caráter.

Por fim, para integrar valores éticos e de responsabilidade social na cultura organizacional, Robin $e$ Reindenbach (1987) indicam que é preciso, primeiramente, desenvolver perspectivas de ética nos negócios e responsabilidade social corporativa para que assim, os valores possam ser incorporados à cultura organi- 
zacional. Essas perspectivas dizem respeito à seleção de valores pertinentes e aos níveis de performance na atuação, ou seja, quais valores farão parte da cultura organizacional e quais os limites de abrangência e de profundidade. O passo seguinte consiste em colocar esses elementos em uma declaração de missão que explicite o perfil ético desejado, perfil este que vai projetar, para o público que interage com a organização, a forma escolhida para essa interação.

Assim, com base na nova missão, elabora-se um novo planejamento estratégico. Durante a implementação deste novo planejamento, a presença dos valores éticos e de responsabilidade social pode fazer com que eles sejam inseridos em cada indivíduo da organização. A adoção desses valores pelos indivíduos durante o desempenho de seus papéis como funcionários torna possível a mudança na cultura organizacional. (ROBIN; REIDENBACH, 1987)

Com relação à inclusão da responsabilidade social e da ética no planejamento estratégico, ressalta-se que é importante que estejam inseridas não apenas nas pessoas que implementam, mas principalmente nas pessoas que formulam a estratégia, ou seja, que as pessoas que elaboram e comunicam as políticas relativas à ética e à responsabilidade social da organização abracem seus ideais tanto no trabalho quanto na vida pessoal. (VITELL; PAOLILLO; THOMAS, 2003; HIGUCHI; VIEIRA, 2012)

\subsection{Recorte Histórico e Marcos Teóricos em Marketing Social Corporativo (MSC)}

Tendo em vista a discussão realizada até o presente momento, estão apresentado a seguir os marcos teóricos em MSC e suas respectivas datas de publicação.

\section{a) Linha do tempo no mundo:}

1950 - Responsabilidade Social Empresarial 1953 - Bowen - livro (considerado o marco inicial do entendimento de RSE)

1962 - Friedman - livro (responsabilidade das empresas: gerar lucro)

1979 - Carroll - artigo (quatro categorias de desempenho social da organização)

1970 - Marketing Social

1952 - Wiebe - artigo (avaliação de quatro campanhas para a mudança social)
1969 - Kotler e Levy - artigo (ampliam os domínios do conceito de marketing)

1971 - Kotler e Zaltman - artigo (conceituam Marketing Social)

Alan Andreasen, James Mintz, Bill Noveli, William Smith

1989 - Kotler e Roberto - livro (estratégias para alterar o comportamento público no marketing social)

1980 - Marketing de Causa Social

1983 - Jerry Wells (da American Express Company, cunhou o termo Marketing Relacionado a Causas)

1988 - Varadarajan e Menon - artigo (apresentação da visão do MCS como um alinhamento entre estratégia de marketing e filantropia corporativa)

1998 - Webb e Mohr - artigo (uma tipologia para as respostas dos consumidores em relação ao MCS)

1990 - Marketing Social Corporativo 1998 - Guardia Massó - livro (MSC: estratégia para a diferenciação das marcas, promovendo benefícios mútuos)

1999 - Pringle e Thompson - livro ((contribuição do Marketing para causas sociais (entendendo-se como Marketing Social Corporativo) na construção de uma marca))

1999 - Adkins - livro ((desenvolvimento de MCS (entendendo-se como MSC) eficaz) 2004 - Maignan e Ferrel - artigo (proposta de um modelo integrativo entre RSC e MKT)

2005 - Saiz - livro (MSC como a ação social da empresa integrada a estratégia corporativa)

\section{b) Linha do tempo no Brasil:}

Responsabilidade Social Empresarial 1957 - ADCE - publicação da Carta de Princípios do Dirigente Cristão de Empresas (função social das empresas)

Marketing Social

1981 - Mazzon - tese de doutorado

1992 - Kotler e Roberto - livro traduzido (Marketing Social) 
Marketing de causa social

2003 - $1^{\circ}$ Seminário Internacional de Marketing Relacionado a Causas no Brasil (com palestra de Adkins com o tema: "Usando o poder da marca para fazer a diferença")

Marketing social corporativo

2000 - Pringle e Thompson - livro traduzido(contribuição do Marketing para causas sociais - entendendo-se como Marketing Social Corporativo - na construção de uma marca

\subsection{Nomenclatura e Categorias de Análise Convergentes em Marketing Social Corporativo (MSC)}

$\mathrm{Na}$ literatura de marketing social corporativo encontram-se diferentes nomes para o mesmo conceito. Neste trabalho foi convencionada uma nomenclatura para os conceitos presentes nas ações sociais, baseada em revisão de literatura, que é mencionada a seguir.

A ética empresarial é constituída por valores que representam a expectativa da sociedade e de todos os outros stakeholders quanto à conduta da empresa, chamada por Fan (2005) de contrato social. A ética envolve todas as ações e as omissões, tanto internas quanto externas, permeando toda a empresa, incluindo-se assim, as ações assistenciais, as ações sociais e suas conexões, as quais são explicitadas na sequência. De modo complementar, responsabilidade social corporativa pode ser compreendida como um conjunto de relações, de obrigações e de serviços geralmente aceitos, que se relacionam ao impacto da corporação no bem-estar da sociedade. (ROBIN; REIDENBACH, 1987; AGUINIS; GLAVAS, 2012)

As ações assistenciais são ações pontuais que trazem a noção de caridade. Essas ações constituem o Projeto Assistencial, o qual consolida a dependência da comunidade, sem modificar suas estruturas. São projetos em que "[...] o apoio fornecido pela empresa torna a comunidade dependente, criando assim um ciclo vicioso que impede a emancipação da comunidade" (MACHADO; LAGE, 2002, p. 9). O projeto ou os projetos assistenciais culminam na Filantropia Empresarial que é vinculada ao assistencialismo, que ocorre sem planejamento e sem nenhuma perspectiva de retorno para a empresa e em um benefício parcial aos necessitados.

As ações que visam à mudança na qualidade de vida por meio da adesão, da modificação ou do abandono de práticas, de ideias, de valores ou de comportamentos, compõem o Marketing Social (ARAÚJO, 2001). Essa mudança social proposta pelo Marketing Social, traz benefícios à sociedade (BINNEY; HALL; SHAW, 2003). O Marketing Social envolve mudança, mas requer também que a prática desse mesmo comportamento alterado seja mantida. (O'SHAUGHNESSY, 1996; BINNEY; HALL; SHAW, 2003; DONOVAN, 2011)

As ações sociais se constituem em ações contínuas que trazem a noção de contribuição para a comunidade. Essas ações sociais integram o projeto social ou os projetos sociais que promovem a emancipação da comunidade, modificando suas estruturas, através de ações planejadas. Os projetos sociais reduzem as desigualdades sociais e são incorporados ao planejamento da empresa, beneficiando a sociedade e sendo entendidos como "[...] um compromisso da empresa com a sociedade na busca da melhoria da qualidade de vida da comunidade". (TENÓRIO, 2004, p. 32)

Quando os recursos da empresa são direcionados a uma causa social que depende do engajamento do consumidor ao adquirir produto ou serviço da empresa, caracteriza-se o Marketing de Causa Social (VARADARAJAN; MENON, 1988; FILE; PRINCE, 1998; McALISTER; FERREL, 2002). O Marketing de Causa Social é considerado como ação tática da empresa, pois não está inserido no plano estratégico e na missão da empresa, produzindo benefícios de duração limitada. (McALISTER; FERREL, 2002; IZQUIERDO, 2005)

Quando se envolve a concepção de Responsabilidade Social desenvolvida sob a perspectiva de Marketing, para fortalecer a marca em benefício mútuo com a causa social (SILVA; LEITE; CAÑADILLA, 2004) constitui-se no Marketing Social Corporativo. Assim, o Marketing Social Corporativo "[...] é um modo muitíssimo eficaz de tornar visível a responsabilidade social de uma corporação" (ADKINS, 2005, p. 493). O Marketing Social Corporativo é uma ação estratégica que produz benefícios para a sociedade e, ao mesmo tempo, cria um retorno para a empresa, traduzindo-se em benefícios de duração em longo prazo. O Marketing Social Corporativo representa o desenvolvimento de 
uma atividade empresarial de interesse social, favorecendo ao mesmo tempo os interesses da sociedade e da empresa, particularmente no que se refere à sua posição no mercado e sua imagem. (MASSÓ, 1998; GARCIA; GIBAJA; MUJIKA, 2001; SILVA; AZKUENAGA; CAÑADILA, 2001)

\section{Esquema Conceitual de Marketing Social Corporativo: uma proposição}

Esta seção compreende a apresentação de um esquema conceitual de marketing social corporativo. Para tanto, ela expõe pressupostos, taxonomia, proposições básicas e aplicabilidade do esquema, conforme de verifica a seguir.

\subsection{Pressupostos do Esquema}

O esquema aqui proposto considera, primeiramente, que as normas sociais são a base das regras que determinam as relações entre a corporação e a sociedade, sejam elas econômicas ou sociais. Na sociedade estão inseridos todos os atores envolvidos, que são a própria corporação, os stakeholders, os desfavorecidos, as causas e as organizações de filantropia.

Pressupõe-se, também, que essas normas sociais não excluem a possibilidade das ações sociais executadas pelas empresas visarem resultados financeiros, desde que elas sejam executadas de modo transparente, conforme os preceitos éticos de conduta, trazendo benefícios para todas as partes envolvidas. O esquema expõe as alternativas de ações sociais executáveis pela corporação, classificadas entre lucrativas e não lucrativas, para o longo e para o curto prazo, bem como os requisitos básicos necessários para a implementação de cada tipo de ação.

Outro pressuposto do esquema é que as corporações conheçam qual a percepção de seus consumidores com relação à imagem corporativa, e se essa imagem precisa ser alterada ou reforçada pelo marketing social corporativo, a fim de se adequar aos objetivos estratégicos. Essa informação sobre a percepção pode ser conseguida através da pesquisa do consumidor, que pode também fornecer subsídios sobre os melhores canais e conteúdos de comunicação. A seguir mostra-se a representação gráfica do esquema.

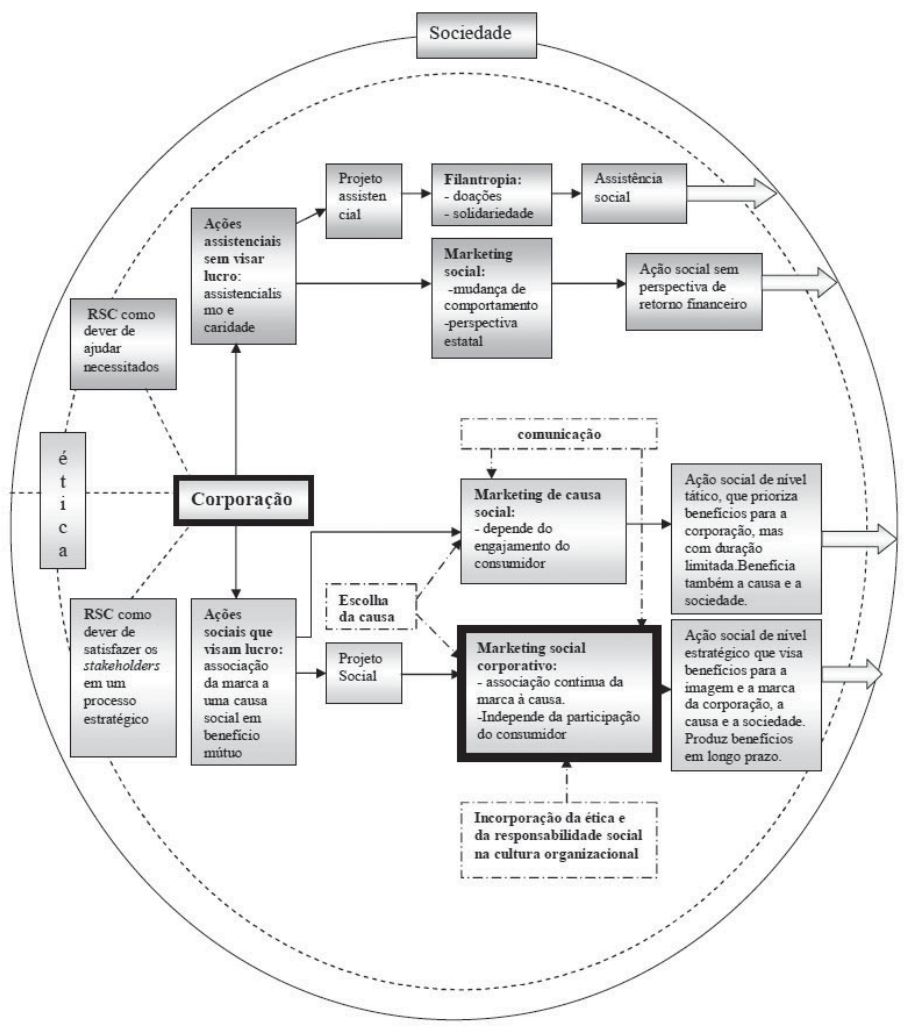

Figura 2: Esquema conceitual de MSC

Fonte: Elaborada pelos autores deste artigo 


\subsection{Taxonomia e Proposições Básicas do Esquema}

No esquema sugerido, a linha contínua externa que forma o círculo maior representa a sociedade, onde se encontram os atores envolvidos. A linha pontilhada que forma o círculo menor representa o domínio das ideias, onde se encontram os princípios éticos. As setas contínuas representam as opções em ações que a corporação possui, enquanto as linhas pontilhadas mostram as concepções que devem ser envolvidas na execução dessas ações. Os retângulos desenhados com linha contínua representam os conceitos apresentados no referencial teórico, enquanto os retângulos desenhados com travessão e ponto mostram os requisitos, citados na literatura, que são importantes para a realização dos programas em marketing de causa social e marketing social corporativo. As setas largas indicam as ações que ultrapassam o domínio das ideias e chegam até a sociedade de forma concreta.

É indicada também, por meio da linha pontilhada que liga a sociedade à ética, a influência da sociedade na definição do que é considerado um comportamento ético e seus desdobramentos nos conceitos de responsabilidade social corporativa e na corporação. Para Fan (2005), a ética nos negócios demanda que as organizações se comportem conforme uma filosofia moral, que precisa estar presente no contrato social firmado entre a corporação e a sociedade na qual ela executa suas atividades. Tal contrato é o elemento principal da responsabilidade social corporativa. Então, o esquema mostra a necessidade das ações sociais, advindas do marketing social corporativo, compartilharem a ética, pois assim assegura-se que elas estão seguindo o contrato social.

O esquema propõe, basicamente, como as questões sociais perpassaram os esforços de marketing da corporação, com as opções partindo de iniciativas assistencialistas sem a intenção de lucro, até chegar ao marketing social corporativo, onde tanto a corporação quanto a causa e os consumidores têm seus objetivos realizados. As iniciativas assistencialistas, que não visam à emancipação da sociedade, possuem o inconveniente de serem aplicáveis somente em situações especiais, em que a ajuda aos necessitados realmente é imprescindível. Já o marketing social pode ser executado em qualquer tempo, com abrangência global, normalmente em parceria com organismos governa- mentais, mas sem trazer para a corporação retornos financeiros, o que pode ser visto como inconveniente por certos stakeholders.

Como a corporação tem como obrigação inicial gerar mais receitas do que custos, ou seja, ela precisa gerar lucros (DRUCKER, 1996), ela não deve ser considerada não ética ao executar programas sociais em que também é beneficiada economicamente. Porém, deve-se observar que dentre as opções possíveis, o marketing de causa social é mais vulnerável à desconfiança do consumidor, uma vez que as ações sociais nesta modalidade são pontuais e com duração limitada. No marketing de causa social, a probabilidade de o consumidor interpretar a empresa como oportunista é maior, por isso a indicação dos requisitos da comunicação e da escolha da causa com a qual se associa. O cuidado na comunicação da associação e a escolha de uma causa alinhada com a imagem corporativa podem diminuir o ceticismo do consumidor.

A eliminação do ceticismo do consumidor ( $\mathrm{DOH}$ et al., 2010) e a satisfação do maior número possível de stakeholders podem ser conseguidas com o marketing social corporativo. Nesse caso, a inserção da ética e da responsabilidade social na cultura organizacional possibilita ações sociais originadas no nível estratégico da organização (FARIA; SAUERBRONN, 2008), inseridas no planejamento estratégico com o intuito de trazer benefícios em longo prazo para a corporação, a causa $e$ a sociedade (MENDONÇA; SCHOMMER, 2000; HIGUCHI; VIEIRA, 2012). Esse requisito, juntamente com a escolha de uma causa que se identifique com a imagem corporativa e a comunicação clara e diferenciada para cada stakeholder, traduz-se em programas consistentes, com resultados que promovem a melhoria da sociedade e proporcionam vantagem competitiva para a corporação em longo prazo.

\subsection{Aplicabilidade do Esquema}

O esquema proposto pode ser aplicado tanto em pequenas organizações, de alcance local ou regional que executam programas únicos, quanto em grandes corporações, que executam vários programas simultâneos para as suas diferentes marcas. Não existem limitações com relação ao ramo de atividade, ao tipo de estrutura de capital ou ao tempo de atividade da empresa. 
O esquema pode servir como referência para o alcance do posicionamento desejado que minimize as possibilidades da criação do ceticismo pelo consumidor (O'SHAUGHNESSY, 1996; GORDON, 2011). Pode direcionar pesquisas de monitoramento ou de resultados das ações ao indicar os requisitos necessários para a implementação de programas de caráter social. Em suma, ele pode responder a questóes como: de que forma a corporação entende a sua responsabilidade perante as diferentes comunidades? Se a corporação não objetiva lucrar veladamente com as ações sociais, como explicitar e posicionar suas ações por meio de comunicação? Como a corporação pode atuar no seu entorno ou de modo regional ou nacional? Em quais causas sociais ou em quais possíveis programas sociais podem ser obtidas vantagens competitivas? Como trabalhar de forma sustentável e contínua?

Dentre as opções existentes, o marketing social corporativo é o que mais possui requisitos, sendo o de mais complexa implementação, exigindo inclusive grande esforço gerencial para articular os diferentes interesses envolvidos. Porém, a princípio, seus possíveis benefícios também são maiores e, principalmente, mais duradouros.

\section{Considerações Finais}

A construção e a proposição de um esquema representa um desafio para acadêmicos e praticantes, pois requer a utilização de critérios de consistência. Essa preocupação, como verificado anteriormente, está contida no presente trabalho, especialmente na reconstrução teórica em torno do tema, na indicação de nomenclatura, nas categorias de análise, na taxonomia, nos pressupostos e na aplicabilidade do esquema.

Diante de um cenário onde coexistem diferentes conceituações sobre os elementos que compõem o marketing social corporativo, o presente esquema pode contribuir em dois aspectos principais, tanto no que se refere a interesses de acadêmicos quanto de praticantes. O primeiro refere-se à construção teórica do conceito de marketing social corporativo que ainda é muito recente, principalmente no Brasil, requerendo mais estudos teóricos e empíricos. Nesse sentido, o esquema proposto auxilia na elucidação de nomenclaturas e nas definições de cada conceito específico, permite uma visualização dos marcos teóricos concernentes ao marketing social corporativo e, sobretudo, assinala uma concepção, já que sugere uma linha de ação para o desenvolvimento e a implementação de programas de marketing social corporativos.

Um segundo aspecto em que o esquema pode contribuir está relacionado às práticas empresariais do marketing social corporativo. Em convergência com os objetivos propostos, esse esquema conceitual permite que as corporações definam qual a melhor estratégia para o direcionamento de suas ações sociais. Isso está posto ao longo do presente artigo, particularmente por meio da exposição de outros conceitos que deram origem ao marketing social corporativo, bem como suas principais características.

A discussão realizada no âmbito desse artigo representa, em última análise, um esforço no sentido de superar uma visão reducionista do desenvolvimento de ações sociais por parte das empresas, particularmente quando tais ações são colocadas sob uma perspectiva de marketing. É claramente possível trabalhar uma nova perspectiva de marketing vinculada ao desenvolvimento de programas e ações sociais tendo em vista um processo de valorização de marcas, posicionamento de conceito e imagem corporativa que transcenda os limites das primeiras formas de ação social concebidas para a atividade de marketing.

Algumas sugestões para futuras pesquisas relacionam-se à possibilidade de investigar o uso da nomenclatura ligada ao universo da prática de ações sociais no Brasil sob a perspectiva de marketing. Certamente tal investigação ajudaria a compreender o universo particular da ação brasileira $e$ indicaria possibilidades de refinamento na construção teórica sobre marketing social corporativo. Outra possibilidade de pesquisa diz respeito à verificação da relação entre adoção de programas e desenvolvimento de ações sociais sob a ótica de marketing social corporativo e a performance financeira decorrente dela. Essa possibilidade contribuiria para definir resultados na proposição conceitual de marketing social corporativo.

Ressalta-se, por fim, que não se discute aqui o caráter ontológico das ações de marketing social corporativo, pois essa não é a intenção do artigo. Destaca-se que o presente trabalho procurou introduzir um esquema conceitual inédito para marketing social corporativo a partir de uma perspectiva baseada na re- 
alidade empresarial brasileira, que tem sido permeada por ações de caráter social, tanto por parte de corporações nacionais quanto transnacionais, representando, seja do ponto de vista empírico, seja do ponto de vista teórico, importante questão de pesquisa para a área de marketing, a qual tem sido pouco explorada e ainda não está organizada e sistematizada em termos de conhecimento em marketing. A profusão de concepções e de conceitos e a falta de convergência e de rigor analíticos sobre eles confirmam essa realidade e a relevância de se tratar o tema.

\section{REFERÊNCIAS}

ADKINS, S. Marketing de causas sociais: quem se importa, ganha. In: BAKER, Michael J. (Org.).

Administração de marketing: um livro inovador e definitivo para estudantes e profissionais. Rio de Janeiro: Elsevier, 2005. p. 477-494.

AGUINIS, H.; GLAVAS, A. What we know and don't know about corporate social responsibility: a review and research agenda. Journal of Management, Thousand Oaks, v. 38, n. 4, p. 932-968, 2012.

ALVES, E. A. Dimensões da responsabilidade social da empresa: uma abordagem desenvolvida a partir da visão de Bowen. RAUSP - Revista de Administração, São Paulo, v. 38, n. 1, p. 37-45, 2003.

ANDREASEN, A. R. The life trajectory of social marketing: some implications. Marketing Theory, London, v. 3, n. 3, p. 293-303, 2003.

ANGELIDIS, J. P.; IBRAHIM, N. A. Social demand and corporate strategy: a corporate social responsibility model.

Review of Business, New York, v. 15, n. 1, p. 7-10, 1993.

ARAÚJO, E. T. de. Estão "assassinando" o Marketing Social? Uma reflexão sobre a aplicabilidade deste conceito no Brasil. REAd - Revista Eletrônica de Administração. Porto Alegre, v. 7, n. 5, p. 1-12, 2001.

ASHLEY, P. A.; MACEDO-SOARES, T. D. L. A. Um modelo conceitual para incorporação da responsabilidade social à governança das relações negócio-sociedade. In: EnANPAD - ENCONTRO ANUAL DA ANPAD, 25., 2001, Campinas. Anais... Campinas: ANPAD, 2001, CD-ROM.
BARONE, M. J.; MIYAZAKI, A. D.; TAYLOR, K. A. The influence od cause-related marketing on consumer choice: does one good turn deserve another? Journal of the Academy of Marketing Science, East Lansing, v. 28, n. 2, p. 248-262, 2000.

BATES, C. Use of social marketing concepts to evaluate ocean sustainability campaigns. Social Marketing

Quarterly, Thousand Oaks, v. 16, n. 1, p. 71-96, 2010.

BINNEY, W.; HALL, J.; SHAW, M. A further development in social marketing: application of the MOA framework and behavioral implications. Marketing Theory, London, v. 3, n. 3, p. 387-403, 2003.

BRONN, P. S.; VRIONI A. B. Corporate social responsibility and cause-related marketing: an overview. International Journal of Advertising, Oxford, n. 20, n. 2, p. 207-222, 2001.

BROWN, T. J.; DACIN, P. A. The company and the product: corporate associations and consumer product responses. Journal of Marketing, Chicago, v. 61, n. 1, p. 68-84, 1997.

COLLINS, M. Global corporate philanthropy - marketing beyond the call of duty? European Journal of Marketing, Bingley, v. 27, n. 2, p. 46-58, 1993.

DAWKINS, J. Corporate responsibility: the communication challenge. Journal of communication management, Bingley, v. 9, n. 2, p. 108-119, 2004.

DOH, J. P.; HOWTON, S. D.; HOWTON, S. W.; SIEGEL, D. S. Does the market respond to an endorsement of social responsibility? The role of institutions, information and legitimacy. Journal of Management, Thousand Oaks, v. 36, n. 6, p. 1461-1485, 2010.

DONOVAN, R. Social marketing's myth understandings. Journal of Social Marketing, Bingley, v. 1, n. 1, p. 8-16, 2011.

DOUGLAS, M. Purity and danger: an analysis of concepts of pollution and taboo. London: Routledge \& Kegan Paul, 1966.

DRUCKER, P. Sociedade Pós-Capitalista. 5. ed. São Paulo: Pioneira, 1996. 
FAN, Y. Ethical branding and corporate reputation.

\section{Corporate Communications: An International}

Journal, Bingley, v. 10, n. 4, p. 341-350, 2005.

FARIA, A.; SAUERBRONN, F. F. A responsabilidade social é uma questão de estratégia? Uma abordagem crítica.

Revista de Administração Pública, Rio de Janeiro, v. 41, n. 6, p. 1-13, 2008.

FILE, K. M.; PRINCE, R. A. Cause related marketing and corporate philanthropy in the privately held enterprise.

Journal of Business Ethics, New York, v. 17, n. 14, p. 1.529-1.539, 1998.

FREITAS, A. G. G.; REZENDE, D. C. de. Marketing social corporativo - MSC e consumo consciente. REMark -

Revista Brasileira de Marketing, São Paulo, v. 9, n. 3, p. 27-48, 2010.

FRIEDMAN, M. Capitalism and freedom. Chicago: University of Chicago Press, 1962.

FOX, K. F. A.; KOTLER, P. The marketing of social causes: the first 1o years. Journal of Marketing, Chicago, v. 44, n. 4, p. 24-33, 1980.

GARCÍA, C. B. Marketing con causa, marketing sin efecto: el marketing con causa y la educación para el desarrollo. Madrid: Universidad de Comillas, 2001.

GARCÍA, I.; GIBAJA, J. J.; MUJIKA, A. Marketing social corporativo: la respuesta a una demanda social. Estudios Empresariales, Deusto, n. 105, p. 26-32, 2001.

GORDON, R. Critical social marketing: definition, application, and domain. Journal of Social Marketing, Bingley, v. 1, n. 2, p. 82-99, 2011.

HASTINGS, G. Relational paradigms in social marketing. Journal of Macromarketing, Thousand Oaks, v. 23, n. 1, p. 6-15, June, 2003.

HASTINGS, G.; SAREN, M. The critical contribution of social marketing: theory and apllication. Marketing Theory, London, v. 3, n. 3, p. 305-322, 2003.

HOEFFLER, S.; KELLER, K. L. Building brand equity through corporate societal marketing. Journal of Public Policy \& Marketing, Chicago, v. 21, n. 1, p. 78-89, 2002.
HIGUCHI, A. K.; VIEIRA, F. G. D. Responsabilidade social corporativa e marketing social corporativo: uma proposta de fronteira entre estes dois conceitos. Acta Scientiarum. Human and Social Sciences, Maringá, v. 34, n. 1, p. 31-40, 2012.

IZQUIERDO, B. G. Análisis de las implicaciones del marketing con causa para las ONGD: desde una perspectiva ética, estética y estratégica. IIG Instituto Internacional de Governabilidad. Disponível em: < http:// www.iigov.org/cpd/?p=31c > . Acesso em: $1^{\circ}$ abril 2005.

KOTLER, P. Marketing para organizações que não visam lucro. São Paulo: Atlas, 1978.

KOTLER, P.; ZALTMAN, G. Social marketing: an approach to planned social change. Journal of Marketing, Chicago, v. 35, n. 3, p. 3-12, 1971.

LERNER, D. L.; FRYXELL, E. G. An empirical study of the predictions of corporate social performance: a multidimensional analysis. Journal of Business Ethics, New York, v. 7, p. 951-959, 1988.

MACHADO, A. L. C.; LAGE, A. C. Responsabilidade social: uma abordagem para o desenvolvimento social. O caso da CVRD. In: ENANPAD - ENCONTRO ANUAL DOS PROGRAMAS DE PÓS-GRADUAÇÃO EM ADMINISTRAÇÃO, 26., 2002, Salvador. Anais... Salvador: ANPAD, 2002, p. 1-14. 1 CD-ROM.

McALISTER, D. T.; FERREL, L. The role of strategic philanthropy in marketing strategy. European Journal of Marketing, Bingley, v. 36, n. 5/6, p. 689-705, 2002.

MAIGNAN, I.; FERRELL, O. C. Corporate social responsibility and marketing: an integrative framework. Journal of the Academy of Marketing Science, East Lansing, v. 32, n. 1, p. 3-19, 2004.

\section{MASSÓ, R. G. El benefício de compartir valores:} marketing social corporativo, una nueva estrategia para diferenciar las marcas. Bilbao: Deusto, 1998.

MAZZON, J. A. Marketing Social: conceitos e perspectivas de utilização no Brasil. Revista de Administração da USP, São Paulo, v. 17, n. 4, p.5-22, 1982. 
MENDONÇA, P.; SCHOMMER, P. C. O marketing e sua relação com o social: dimensões conceituais e estratégicas e o caso de duas organizações em interação. In: ENANPAD - ENCONTRO ANUAL DOS PROGRAMAS DE PÓS-GRADUAÇÃO EM ADMINISTRAÇÃO, 24., 2000, Florianópolis. Anais... Florianópolis: ANPAD, 2000, p. 1-12. 1 CD-ROM.

MORETTI, S. L. do A.; FIGUEIREDO, J. B. Análise bibliométrica da produção sobre responsabilidade social das empresas no EnANPAD: evidências de um discurso monológico. RGSA - Revista de Gestão Social e Ambiental, São Paulo, v. 1, n. 3, p. 21-38, 2007.

MORETTI, S. L. do A.; CAMPANÁRIO, M. de A. A produção intelectual brasileira em responsabilidade social empresarial - RSE sob a ótica da bibliometria. Revista de Administração Contemporânea, Rio de Janeiro, v. 13, n. especial, p. 68-86, 2009.

MORETTI, S. L. do A. O marketing e o social nos bancos brasileiros: evidências de relações assimétricas. REMark - Revista Brasileira de Marketing, São Paulo, v. 9, n. 1, p. 124-150, 2010.

O'SHAUGHNESSY, N. Social propaganda and social marketing: a critical difference? European Journal of Marketing, Bingley, v. 30, n. 10/11, p. 54-67, 1996.

PEATTIE, K.; PEATTIE, S. Social marketing: a pathway to consumption reduction? Journal of Business

Research, Atlanta, v. 62, n. 2, p. 260-268, 2009.

PINTO, M. R.; PEREIRA, D. R. M.; LARA, J. E. Caracterização de perfis de empresas quanto à adoção de práticas de responsabilidade social. In: XXVIII ENANPADEncontro Nacional dos Programas de Pós-Graduação em Administração, set. 2004, Curitiba. Anais... Curitiba: ANPAD, 2004, CD-ROM.

PRADO, L. S. do; MERLO, E. M.; CERIBELI, H. B. Responsabilidade social corporativa: um estudo do processo de comunicação dos varejistas brasileiros. REMark - Revista Brasileira de Marketing, São Paulo, v. 9, n. 2, p. 23-40, 2010.

\section{PRINGLE, H.; THOMPSON, M. Marketing social:} marketing para causas sociais e a construção de marcas. São Paulo: Makron Books, 2000.
PTACEK, J. J.; SALAZAR, G. Enlightened self-interest: selling business on the benefits of cause-related-marketing. Nonprofit World, Atlanta, v. 15, n. 4, p. 9-13, 1997.

ROBIN, D. P.; REIDENBACH, E. Social responsibility, ethics, and marketing strategy: closing the gap between concept and application. Journal of Marketing, Chicago, v. 51, n. 1, p. 44-58, 1987.

SAIZ, F. J. B. Marketing social corporativo: la acción social de la empresa. Madri: Pirámide, 2005.

SEN, S.; BHATTACHARYA, C. B. Does doing good always lead to doing better? Consumer reactions to corporate social responsibility. Journal of Marketing Research, Chicago, v. 38, n. 2, p. 225-243, 2001.

SILVA, J. A. R.; AZKUENAGA, X. Z.; CAÑADILA, I. P. Marketing social e as ONGD's de comércio justo. In: ENANPAD - ENCONTRO ANUAL DOS PROGRAMAS DE PÓS-GRADUAÇÃO EM ADMINISTRAÇÃO, 25., 2001, Campinas. Anais... Campinas: ANPAD, 2001, p. 1-15. 1 CD-ROM.

SILVA, J. A. R.; LEITE, A. P. R.; CAÑADILLA, I. P. Marketing e responsabilidade social corporativa: uma análise de casos de empresas espanholas. In: EMA ENCONTRO DE MARKETING DA ANPAD, 1., 2004, Porto Alegre. Anais ... Porto Alegre: EMA/ANPAD, 2004, p. 1-17. 1 CD-ROM.

SMITH, S. M.; ALCORN, D. S. Cause marketing: a new direction in the marketing of corporate responsibility.

Journal of Consumer Marketing, Bingley, v. 8, n. 3, p. 19-35, 1991.

SMITH, W.; HIGGINS, M. Cause-related marketing: ethics and ecstatic. Business \& Society, Thousand Oaks, v. 39, n. 3, p. 304-322, 2000.

TENÓRIO, F. G. (Org.) Responsabilidade social empresarial: teoria e prática. Rio de Janeiro: Editora FGV, 2004.

VARADARAJAN, P. R.; MENON, A. Cause-related marketing: a coalignment of marketing strategy and corporate philanthropy. Journal of Marketing, Chicago, v. 52, n. 3, p. $58-74,1988$. 
VITELL, S. J.; PAOLILLO, J. G. P.; THOMAS J. L. The perceived role of ethics and social responsibility: a study of marketing professionals. Business Ethics Quarterly, Charlottesville, v. 13, n. 1, p. 63-86, 2003. 